\section{Non-invasive Technologies of Tissue Viability Measurement for Pressure Ulcer Prevention in Spinal Cord Injury}

\author{
Liang Q Liu'*, Rachel Deegan² and Angela Gall² \\ ${ }^{1}$ Department of Adult, Child \& Midwifery, Centre for Critical Research in \\ Nursing and Midwifery, School of Health and Education, Middlesex \\ University, London, UK \\ ${ }^{2}$ London Spinal Cord Injury Centre, Royal National Orthopaedic Hospital, \\ London, UK
}

\section{Introduction}

Developing Pressure Ulcer (PU) is one of the most common secondary complications following Spinal Cord Injury (SCI). It is estimated that more than a half of people living with SCI develop a pressure ulcer during their life-time [1-4]. PU is commonly known as a pressure sore, bed sore or decubitus ulcer, and is described as an area of localised damage to the skin as a result of prolonged pressure alone, or pressure in combination with shearing forces (EPUAP/NAPUAP 2014) [5]. It is typically categorised into four key stages depending on the severity. Once PU is developed, it has substantially detrimental impact on the quality of life, independence, and dignity of a patient [5-7]. If PU is severe, it can lead to further disabilities, need for surgical interventions and even fatal infections [7]. Apart from personal consequences, $\mathrm{PU}$ also represents a significant cost burden for health and social care systems. According to National Institute of Health and Care Excellence (NICE) guideline 2014 [8], in addition to the costs of standard care, the daily costs of treating a pressure ulcer are estimated to range from $£ 43$ to $£ 374$ in the United Kingdom. Resources required for treating a pressure ulcer include nurse time, dressings, antibiotics, diagnostic tests and high specification pressure redistributing devices. Although exact cost of PU management in SCI is unknown, the total cost of treating PUs has been estimated to be between $£ 1$.4bn and $£ 2.1$ bn per year, with the average cost to treat one Category IV PU being $£ 14,108$ per episode in general population [9]. Given the significant detrimental personal impact and health social cost burden, preventing PU development is vitally important.

Thus far, enormous efforts have been put to prevent PU development in SCI $[8,10]$. For instance, use of various specified mattress, cushions help relief pressure over bony prominences; patients are required to improve diet and reposition regularly. Heath professionals have been constantly looking for the best clinical risk assessment tools to monitor these patients. Yet, despite the extreme expensive equipment together with tremendous staff time, the incidence of PU remains unacceptably high in SCI [1-4].

Indeed, effective PU prevention strategies are based on a thorough understanding of pathological changes following SCI that leads to PU formation. While PU development is undoubtedly multifactorial in individuals with different pathological conditions, the prolonged pressure loading sufficient to produce ischemia, cell deformation, lymphatic impairment and reperfusion injury has been identified as important process of PU formation [11]. Following SCI, loss of mobility results prolonged lying or sitting for their daily activities. The interruption of spinal vasomotor pathways results in the loss of vasomotor control over skeletal muscle and skin, which lowers the tone of the vascular bed below the level of the lesion. The impaired vascular patency causes the vessels to be less able to withstand normal loading conditions. Concurrent with the loss of capillary networks due to lost muscle bulk, the volume of blood in the tissues is reduced [11-13]. Considering microcirculation being crucial for tissue viability in terms of supply of oxygen and nutrients and removal of waste products, interrupted microcirculation leads to ischemia and local tissue starvation. Moreover, following SCI, lack of sensation below the level of injury leads to insensitivity to the ischemia which consequently leads to greater risk of PU formation. The ability of
Received: July 08, 2015; Accepted: August 28, 2015; Published: September 18, 2015
*Corresponding author: Liang Q Liu, Department of Adult, Child \& Midwifery Centre for Critical Research in Nursing and Midwifery, School of Health and Education, Middlesex University, Hendon Campus, Williams Building E-mail: L.Q.Liu@mdx.ac.uk

Citation: Liu LQ, Deegan R, Gall A (2015) Non-invasive Technologies of Tissue Viability Measurement for Pressure Ulcer Prevention in Spinal Cord Injury. J Phys Med Rehabil Disabil 1: 002. 
quantitative assessment of tissue integrity plays a key role for PU prevention. Therefore, robust objective assessment tools to detect or monitor early sign of PU are needed.

As early as 1980s, Levine and associates measured blood flow of gluteal muscle in response to electrical stimulation in eight nondisabled subjects and six subjects with SCI [14]. They found that all subjects showed increased muscle blood flow during stimulation, but the increase was greatest for the nondisabled group. In their study, the blood flow was measured by injecting radioactive element and measuring Xenon133 clearance. Such an invasive technique has significant drawbacks for clinical and research applications. Since 1990s, a variety of non-invasive technologies have been explored on skin blood perfusion and/or tissue integrity assessment for research purpose on PU prevention in SCI. In comparison to subjective clinical risk assessment tools, non-invasive technologies monitoring risk of PU formation have enormous potentials in terms of accuracy, cost effectiveness for both staff and patients on PU prevention.

The purpose of this review is to provide basic explanations of some non-invasive technology concepts, a brief review of applications of these non-invasive modalities for measuring risk of PU formation in SCI, and provides an insight into topics for further application and exploration.

\section{Search Method}

Key words for electronic database (PubMed) search included SCI, tissue integrity and PU. Search terms for SCI included quadriplegi* ${ }^{*}$, tetraplegi $i^{\star}$, paraplegi $i^{*}$, spinal cord trauma ${ }^{*}$, and spinal cord injury ${ }^{*}$. Search terms for PUs were: pressure sore ${ }^{\star}, \mathrm{PU}^{*}$, decubitus ulcer ${ }^{*}$, ischemic ulcer*, bed sore ${ }^{\star}$, and skin sore* Search terms for tissue integrity were: blood flow, blood perfusion, tissue integrity, tissue viability and tissue health, The National PU Advisory Panel (NPUAP), European PU Advisory Panel (EPUAP), National Institute for Health and Clinical Excellence (NICE) were searched for relevant published guidelines. In addition, the reference list of included studies and other relevant papers (eg: available reviews) were screened to identify relevant studies.

\section{Literature Review}

\section{Laser Doppler Flowmetry (LDF)}

Laser Doppler technique was first described by Stern in 1975 [15]. It utilises the frequency shift of laser light in response to the movement of red cells for measuring blood flux. Principally, LDF is based on the fact that when a coherent, low-powered laser illuminates tissue, light is scattered in static structures as well as in moving blood cells within the microcirculatory beds. Photons scattered by the moving blood cells, are spectrally broadened according to the Doppler Effect. In practice, when light is applied to the surface of skin via a fibre optic probe, the back-scattered light is picked up by detectors via a separate fibre in the probe. Laser light determines perfusion quantities in tissue. A Doppler shift is caused by the movement of erythrocytes. The magnitude and frequency of dermal distribution of the shifted laser light is related to the number and velocity of moving blood cells, regardless the direction of movement. The returned signal is analysed by the instrument giving a value of blood cell movement, which is called blood flux. The blood flux is defined by the product of the number of moving blood cells in the sample volume and their velocity. It is expressed in arbitrary units and considered a relative indicator of cutaneous blood flow. In general, LDF can monitor microvascular perfusion up to 0.5-1 mm deep underneath the skin and record blood flux in a skin section of about $1 \mathrm{~mm}^{3}$. The sample volume comprises capillaries and more deeply localized shunt vessels. A concise review of the developments in laser Doppler methods has been described previously $[16,17]$.

LDF has been extensively used by researchers to measure tissue perfusion across many medical realms [16,17]. It is also expended to certain clinical applications. For instance, in plastic surgery, LDF have been used to monitor perfusion in free skin flaps and has proved useful in providing early indications of reduced perfusion and flap vulnerability, before clinically observed signs [17]. LDF is widely used by researchers as well to assess microvascular function in SCI [18-26]. Back to 1990s, Schubert and Fagrell [18] used LDF to examine the response of skin blood cell flux to locally applied pressure over the sacrum and the gluteus maximus muscle in 20 patients with SCI (10 with tetraplegia, 10 with paraplegia) and 10 healthy subjects. They observed that people with SCI have an impaired hyperaemic response, and concluded that the impairment is related to the loss of sympathetic tone over the microvascular system. Most recently, Sonenblum and colleagues [19] investigated the effectiveness and interactions of two methods of pressure ulcer prevention, wheelchair cushions and pressure relief manoeuvres on blood perfusion of the buttocks of seventeen SCI. They found that regardless of the cushion being used, the conventional pressure relief manoeuvres with full and intermediate leans in both forward and sideward directions resulted in significant increases in buttock blood flow. But the small frontward lean was shown to be ineffective in increasing blood flow. Hence, they suggested that clinical instruction should cover those intermediate leans in both forward and sideward directions to impart sitting behaviours that may lead to better tissue health.

LDF is an accurate and reliable method for assessing microcirculatory function and offers advantages of non-invasive measurement. It provides real-time measurement of skin blood perfusion as well as microvascular dynamic function, such as blood flow oscillations reflecting vasomotor and microvascular control mechanisms. LDF causes no harm or disturbance of the normal physiological state of microcirculation. However, LDF has its own disadvantages. One major limitation of LDF is that it does not measure absolute perfusion values. LDF measures cutaneous blood flux rather than blood flow, a relative indicator of cutaneous blood flow. Although some researchers have tried to convert millivolts to conventional blood flow units using theoretical calculations, this is not widely accepted. Measurements in most studies are expressed as arbitrary perfusion units or millivolts ( 1 perfusion units $=10 \mathrm{mV}$ ) and are often referred to as flux rather than flow. Cracowski and colleagues recommended a more physiological approach by expressing LDF data as conductance (i.e., flux divided by arterial pressure (in $\mathrm{mV} / \mathrm{mmHg}$ )) to take into account differences and variations in blood pressure [27]. Yet this does not enable the comparison of absolute flux or conductance values across studies using different probes and/or brand of device and/or sites of measurement. Furthermore, the depth of LDF measurement is about $0.5 \mathrm{~mm}-1 \mathrm{~mm}$, which has significant limitation to measure tissue health below sub-epidermal level, in particular for detecting those deep tissue injuries that develop deep in the tissue and without exhibiting early skin signs. In addition, the rigid probe has to be attached to the tissue and movement of the optic fibre during measurements can result in artefacts and produce erroneously high 
flux readings, which can make the results difficult to interpret, thus limiting its applications for continuous monitoring in bony areas where PU occurs.

\section{Transcutaneous gas tension measurement}

Transcutaneous gas tension measurement is a method of measuring the oxygen and carbon dioxide level in the blood by attaching electrodes to the skin. The technology was advocated by pioneering experimental physiologists who discovered over 150 years ago that human skin can 'breath'. The skin takes up oxygen and gives off carbon dioxide to the surrounding air.

Non-invasive monitoring of oxygen and carbon dioxide has been used for about 40 years [28]. The covered polarographic blood gas electrode for oxygen was first modified for transcutaneous use by Evan and Naylor in 1967 [29]. The electrode was initially used to measure the oxygen level at normal skin surface temperature without heating the underlying skin. They found that the level of oxygen diffusing from the dermal capillaries to the skin surface is mainly controlled by skin blood flow and temperature. If the skin is covered by a flat, unheated oxygen tension $\left(\mathrm{pO}_{2}\right)$ electrode, the surface $\mathrm{pO}_{2}$ falls to zero in a few minutes. However, if the skin blood flow is greatly increased by locally heating the skin to the highest tolerable temperature $\left(45^{\circ} \mathrm{C}\right)$ the surface $\mathrm{pO}_{2}$ rises to approximate the arterial $\mathrm{pO}_{2}$ [30]. As such, this result led to the development of transcutaneous electrodes which incorporated a thermostatically controlled heating element to maximise local blood flow. Transcutaneous measurements of oxygen and carbon dioxide are based on the principle that a heating element in the electrode elevates the temperature of the underlying tissues. This increases the capillary blood flow and the partial pressure of oxygen and carbon dioxide, and makes the skin permeable to gas diffusion. A good relationship between transcutaneous oxygen tension and arterial oxygen tension was demonstrated in neonates and this led to the use of continuous non-invasive transcutaneous oxygen tension monitoring in neonatal intensive care units [31]. Other subsequent studies have also shown that this technology works well for older children and adults $[32,33]$. The transcutaneous electrode for the assessment of carbon dioxide consists of a Stow-severinghaus glass electrochemical sensor that has been modified for transcutaneous use by the incorporation of a thermostatically controlled heater unit as in the transcutaneous oxygen tension electrode [34]. Close correlations between transcutaneous carbon dioxide tension and arterial carbon dioxide tension have again been demonstrated in adults as well as in neonates $[35,36]$.

In order to aid interpreting transcutaneous data, normal values of transcutaneous $\mathrm{PO}_{2}$ and transcutaneous $\mathrm{PCO}_{2}$ in healthy population has been described previously [37,38]. An average of $70 \mathrm{mmHg}$ (45-90 mmHg) for transcutaneous $\mathrm{PO}_{2}$ [37] and an average of $38 \mathrm{mmHg}(30-45 \mathrm{mmHg})$ for transcutaneous $\mathrm{PCO}_{2}$ [38] were identified in the healthy population. When excessive pressure is applied over the skin and soft tissues, a decrease of transcutaneous $\mathrm{PO}_{2}$ and, in some cases, an increase in transcutaneous $\mathrm{PCO}_{2}$ occur due to the local ischemia [39]. Tissue viability thresholds for these changes have been defined for PU risk $[39,40]$ and wound healing [41]. The transcutaneous gas tension measurement has been widely used for research and clinics across many medical fields including PU prevention [17]. In terms of research applications in SCI, transcutaneous gas tension measurement has been used to study microcirculatory changes in SCI since 1980s [42-46]. Mawson and co-investigators compared transcutaneous oxygen tension levels in
21 subjects with spinal cord injury and 11 able-bodied controls lying prone and supine on egg-crate mattresses. They found the transcutaneous oxygen tension level of the SCI group was lower than that in the able-bodied group in the prone position $(65.3+/-16$ $\mathrm{mmHg}$ vs $76.4+/-13 \mathrm{mmHg} ; \mathrm{p}=0.053)$, and markedly lower in the supine position $(49.1+/-26 \mathrm{mmHg}$ vs $74.2+/-10 \mathrm{mmHg}$; $\mathrm{p}=0.004)$. People with SCI had a lower transcutaneous oxygen tension under a constant pressure while healthy controls show an adaptive recovery of oxygenation after 15 minute loading. By measuring both oxygen and carbon dioxide tension in response to regional interface pressures, bogie and colleagues studied 42 subjects who had spinal cord injury (23 above T6, 19 below T6) within 1 year and assessed the effectiveness of prescribed wheelchair cushions in terms of tissue response at the ischial tuberosities [43]. They evaluated oxygen and carbon dioxide tension distributions during sitting under the prevailing active pressure relief regime of the subjects. They reported that SCI individuals with lesions below T6 showed a progressive decrease in ability to maintain blood flow during sitting while SCI subjects with lesions above T6 show a progressive improvement in tissue viability status, therefore they concluded that paraplegics are actually at a potentially higher risk than tetraplegics subjects.

Although this technique offers advantages of providing the real value of oxygen and carbon dioxide level, heating effects of the sensor can potentially cause local erythema or skin burn. In fact, it was reported that more skin burn marks have been seen in clinic follow-ups 20 years ago when the transcutaneous temperature of $44^{\circ} \mathrm{C}$ was used. Due to the heating side effect, $43.5^{\circ} \mathrm{C}$ is now widely recommended [17]. Another disadvantage of this technique is that the rigid probe can potentially increase local pressure when it is applied over bony areas. Therefore, this measurement is limited for continuous application in high pressure loading areas where PU develops. Moreover, the transcutaneous monitoring is relatively expensive and more complicated to use than other techniques.

\section{Tissue Reflectance Spectrometer (TRS)}

TRS is an optical technique for providing detailed measurement of spectrum changes associated with haemoglobin content and oxygenation. The principle of TRS relies on the absorption by haemoglobin, a chromophore absorbing light in the visible range of the spectrum (500-600 nm). TRS uses the characteristic absorption of light by the constituents of skin to measure the amount of various constituents present. Light passes through the epidermis (melanin layer) and a plexus of blood vessels in the epidermis (haemoglobin layer) before being reflected off collagen in the dermis. Haemoglobin $\mathrm{Hb}$ absorbs light with a characteristic curve showing broad bands of absorption spectrum. Oxyhemoglobin (oxyHb) has two maximums at approximately $542 \mathrm{~nm}$ and $574 \mathrm{~nm}$ wavelengths. Deoxyhemoglobin (deoxyHb) shows a single maximum at approximately $545 \mathrm{~nm}$. Thus, TRS can theoretically produce information about both the amount of haemoglobin present and its degree of oxygenation. Anatomically, the human skin is described in terms of 2 different scattering and absorbing layers. The stratum corneum, mainly includes diffuse forward scattering, and influences total skin reflectance by approximately $8 \%$ (Wan et al., [47]) which is negligible. The most dominant layer for scattering is the dermal collagen $[48,49]$. The light penetrating the stratum corneum is heavily absorbed by the epidermal melanin and then the haemoglobin-containing papillary dermis. The absorption spectrum of each of these compounds allows quantitative measurements of their relative concentration to be made. 
By using TRS, Hagisawa and Ferguson-Pell [50] investigated the reactive hyperaemia response in the skin over the great trochanters of able bodied and SCI subjects, and found that the reflow rate after loading was slower in SCI than in able-bodied subjects. Liu and colleagues used TRS to measure skin blood perfusion incorporating a customised probe in spinal cord injury during functional electrical stimulation via a sacral nerve root implant. The customised probe was placed under the ischial tuberosity while individuals were sitting in a wheelchair. They reported an increase in skin blood perfusion over the ischial tuberosities during sacral nerve root stimulation [51].

TRS has its own major advantages of being non-invasive, a real-time and continuous measurement, of not altering the physiological nature by the measurement and being effective for pigmented skin if the effect of melanin can be corrected [52-55] furthermore, and the measurements are not affected by the movement artefact. However, TRS does not provide an absolute value of haemoglobin content or oxygenation. The depth and area of skin measured is relative small (theoretically $0.5 \mathrm{~mm}$ ), which was limited by the light wavelength and the size of probes.

\section{Near-infrared Spectroscopy (NIRS)}

Near-infrared energy was discovered as early as the $19^{\text {th }}$ century and was ascribed by William Herschel. The first industrial application of NIRS was not launched until the 1950s. Initially, NIRS was only used as an add-on unit to other optical devices that used other wavelengths such as ultraviolet, visible, or mid-infrared spectrometers. Up to the 1980s, a single-unit, stand-alone NIRS system was made available. With the introduction of light-fibre optics in the mid-1980s and the monochromator-detector developments in early 1990s, NIRS became a more powerful tool for scientific research. Using near infrared wavelengths (700-1100 nm), NIRS has capability to provide quantitative information on the structural and chemical components of cutaneous tissue, specifically oxygen saturation, haemoglobin content and water content. Technically, NIRS devices illuminate skin tissue at near infrared wavelengths and reflectance of light is collected via fibre optic probes (or by camera in near-infrared imaging). Light in the near-infrared range is absorbed by various skin chromophores specifically water, oxy-haemoglobin, and deoxy-haemoglobin. Deoxy-haemoglobin has a maximum absorption at $760 \mathrm{~nm}$, whereas absorption of oxyhaemoglobin is greatest at $900 \mathrm{~nm}$. Water, which may have implications for identifying oedema, has a peak of absorption at about $980 \mathrm{~nm}$. While some of the penetrating light will be absorbed by these chromophores, some of the light is scattered and reflected by other skin components. NIR reflectance is collected by a detector and analysed to provide measurements of chromophore content. The subsequent analysis of this data can be applied to the assessment of local tissue integrity.

By using NIRS, Jan and co-investigators measured muscle perfusion over the ischial tuberosity by using NIRS during wheelchair tilt-in-space and recline in people with spinal cord injury [56]. Twenty participants were asked to perform pressure relied in wheelchair in six combinations of wheelchair tilt-in-space and recline angles in a random order. The muscle perfusion was significantly increased at $25^{\circ}$ and $35^{\circ}$ tilt-in-space when combined with $120^{\circ}$ recline, while skin perfusion was significantly increased at 3 tilt-in-space angles $\left(15^{\circ}, 25^{\circ}, 35^{\circ}\right)$ when combined with $120^{\circ}$ recline. They concluded that a larger angle of tilt-in-space and recline is needed to improve muscle perfusion compared with skin perfusion. A position of $25^{\circ}$ tilt-in-space combined with $120^{\circ}$ recline is effective in enhancing muscle perfusion of weight-bearing soft tissues at the ischial tuberosities in spinal cord injuries.

Li and colleagues [57] assessed the blood oxygenation oscillations in the tissue over the sacrum using NIRS in ten spinal cord injury ( 3 women, 7 men, age $=34.5 \pm 5.2$ years) and the other ten were healthy subjects ( 3 women, 7 men, age $=36.5 \pm 6.2$ years). Their results showed that the amplitude of the oxygenated haemoglobin and haemoglobin component was significantly lower during the resting conditions in SCI than normal subjects $(\mathrm{p}<0.05)$. During the post-loading period, the response of oxygenated haemoglobin and haemoglobin oscillatory activities were significantly lower in the tissue over the sacrum for persons with SCI than that for normal subjects $(\mathrm{p}<0.05)$. Their results indicated that the low oscillatory activities might be related to early tissue injury in persons with SCI.

In comparison with other optical technologies, one advantage of NIRS is that it can typically penetrate much further into tissue, eg: muscle or bones; therefore it can provide more information of tissue integrity. Such technology has significant potential to aid in wound assessment, specifically the classification of wound depth and the quantification of oedema. The addition of water content measurement to the oxygen and haemoglobin data allows further differentiation, distinguishing between superficial, intermediate partial thickness, deep partial thickness and full thickness wounds [58]. However, such a device is not sensitive when lights near the infrared wavelength range are used to penetrate to deep tissue in a relevant large area. In addition, the dermal probes are relative large and suitability of application over the bony areas is questionable.

\section{Combination modality}

Recently, a device in combination of LDF and TRS techniques has been developed. The equipment called Oxygen-to-See (O2C) uses laser Doppler flowmetry and diffuses reflectance spectroscopy for non-invasive determination of oxygen supply in tissue perfused with blood. The measurement principle of the device relies on a combination of laser-Doppler-technique and tissue spectrometry. Diverse application at the skin, internal organs and in the intestinal tract is possible by flexible glass fibre probes. O2C transmits continuous wave laser light $(830 \mathrm{~nm}$ and $30 \mathrm{~mW})$ and white light $(500-800 \mathrm{~nm} ; 1-\mathrm{nm}$ resolution; $20 \mathrm{~W})$. The sample frequency of the $\mathrm{O} 2 \mathrm{C}$ is $0.5 \mathrm{~Hz}$. The reliability of this modality to measure oxygenation in muscle tissue has been reported by Reenalda et al., [59]. By using this technique, Smit and co-investigators [60] measured gluteal regional blood flow and oxygenation in 12 men with SCI. They compared effects of ES-induced gluteal and hamstring muscle activation with pressure relief movements (push-ups, bending forward and leaning sideward during sitting). Their results showed that all pressure relief movements significantly increased gluteal region blood flow and oxygenation, whereas ES-induced muscle activation only increased for peak blood flow.

This combined technique offers more advantages than single LDF or TRS. It can noninvasively measure the subcutaneous tissue oxygenation up to a depth of $8-10 \mathrm{~mm}$, reaching the muscle tissue. Such technique is suitable for measuring the dynamic response in blood flow in reaction to the changing seating load. However, the equipment is very expensive; the commercial probe is a rigid glass fibre that has potential confounding effect on the measurements. Therefore application on the bony area is questionable. Again the value given is arbitrary rather than local real oxygen level. 


\section{Subepidermal Moisture (SEM) measurement}

The SEM scanner/monitor has been designed to measure the water content of the extracellular space below the surface of the tissue. Using $300 \mathrm{MHz}$ electromagnetic waves it measures subepidermal moisture/localized oedema, determined by dielectric and water content changes which has been investigated for association with erythema, Stage I, and Stage II PUs [61-64], as well as for its ability to differentiate between healthy skin and skin with pressure-induced tissue damage [65]. Subepidermal moisture has also been examined as a predictor of imminent ulceration in various populations $[61,62,66]$.

The principles of measuring dielectric properties of tissue, including capacitance with a coaxial electrode, is a signal is generated by the device and transmitted to the tissue through the sensor. The signal response is affected by dielectric characteristics of the subepidermal tissue and the amount of free and bound water in the tissue, which is compared to internal reference values. The depth of the transmitted signal or the depth of measurement is dependent upon the size of the probe and the applied signal frequency. By using this device, Guihan and co-investigators [63] measured Subepidermal Moisture (SEM) in 34 SCI participants. Twelve participants received daily, 22 received weekly SEM measurement alongside visual skin assessment across nine anatomic locations for up to 6 weeks. They found that SEM was lowest for normal skin (39.3 dermal phase units, $\mathrm{SD}=12.6)$ and higher for erythema/stage 1 PUs (40.8 dermal phase units, $\mathrm{SD}=10.4)$ across all anatomic sites. Buttocks $S E M$ were different between normal skin (40.5 dermal phase units, $S D=10.3)$ and erythema/stage1 PUs (43.8 dermal phase units, $\mathrm{SD}=9.5$ ). SEM taken at heels was lower across all skin conditions (normal skin 28.2 dermal phase units; erythema/stage I PUs 34.7 dermal phase units).

This newly developed modality is portable, hand-held with ease of application. The changes in SEM measured by the device could be utilized for both prevention and detection of PUs. However, the capability of remotely monitoring tissue integrity continuously over the bony area is questionable. The reliability and validity of the measurement still remains unclear so far.

\section{Discussion}

Non-invasive technologies measuring risk of PU formation objectively have enormous potential to aid research in development and implementation of various modalities for preventing PUs. Our review focussed on non-invasive technologies of tissue integrity assessment in SCI. Non-invasive technologies reviewed in this paper measure different tissue parameters including skin/muscle blood perfusion, skin microvascular function and tissue biomechanical properties. The diversity of techniques available indicates the complexity of measuring different aspects of tissue integrity. The four aspects of tissue integrity, which were measured in this review, were physical movement of blood cells, heat transport and the oxygen content of blood and dielectrics values. Undoubtedly, there are many more important aspects of PU prevention and management, such as spasticity, range of motion of the joints, positioning, interface pressure, shear force and the type of surfaces on the bed or wheelchair. However, these aspects are beyond the scope of this review.

Without a doubt, effectively preventing PU is challenging because the combination of pressure and duration that results in tissue damage varies largely among individuals. The underlying damage is often severe by the time a surface ulcer becomes visible, in particular for people with dark skin which is difficult to remark. Currently, no modality exists to detect early tissue damage and enable intervention for preventing PU formation. Yet interestingly, Swisher and colleagues recently developed a flexible, electronic device that non-invasively maps pressure-induced tissue damage in vivo on a rat model. They found that impedance is robustly correlated with tissue health across multiple animals and wound types [67]. Such technology is worthy to further investigate in order to apply on human subjects.

Worth to note, this review is written as a topic scope review. Unlike a systematic review, we did not include quality assessment of articles reviewed, which has limited the depth of our review. And also only one electronic database (PubMed) and relevant guideline websites alongside the hand search was used to identify relevant studies. Nevertheless, the purpose of our review was to present basic information of non-invasive technologies for monitoring risk of $\mathrm{PU}$ formation in SCI, and provide an insight in such topic for further application and exploration.

Finally, our review focussed on non-invasive technologies for research purpose other than clinical practice. Certainly a robust objective assessment tool for detection of early sign of PU ultimately should be practical and realistic in clinical use. However, such aspect was beyond the scope of this topic review. Nevertheless, our current review provided basic information and explained the concept of those technologies that have been applied for research in SCI. These modalities included in our review have potentials for further development in terms of clinical application. To provide level I evidence for clinicians who deal with PU management, future rigorous reviews on such topic incorporating both research and clinical implementation are warranted.

\section{Conclusion}

All currently available techniques applied for risk assessment in SCI have limitations for continuous, real time monitoring of tissue integrities in high risk areas and require further investigation. Subepidermal moisture measurement and combination spectroscopy with LDF has potential for clinical monitoring risk of PU formation application. However, there is lack of evidence of reliability and validity of former technology and high cost for latter technology. A reliable low cost, wearable wireless devices incorporated with current available modalities is warranted for investigation for PU prevention in SCI.

\section{Reference}

1. Chen Y, Devivo MJ, Jackson AB (2005) Pressure ulcer prevalence in people with spinal cord injury: age-period-duration effects. Arch Phys Med Rehabil 86: $1208-1213$

2. Byrne DW, Salzberg CA (1996) Major risk factors for pressure ulcers in the spinal cord disabled: a literature review. Spinal Cord 34: 255-263.

3. Ash D (2002) An exploration of the occurrence of pressure ulcers in a British spinal injuries unit. J Clin Nurs 11: 470-478.

4. Liu LQ, Moody J, Traynor M, Dyson S, Gall A (2014) A systematic review of electrical stimulation for pressure ulcer prevention and treatment in people with spinal cord injuries. J Spinal Cord Med 37: 703-718.

5. National PU Advisory Panel, European PU Advisory Panel (NPUAP/EPUAP) (2009) Prevention and treatment of PUs: clinical practice guideline. National PU Advisory Panel, Washington, DC, USA. Pg: 169.

6. Kloth L, McCulloch JM (2002) Wound Healing: Alternatives in Management, (3rdedn). FA Davies Co., Philadelphia, USA. Pg no: 568. 
Citation: Liu LQ, Deegan R, Gall A (2015) Non-invasive Technologies of Tissue Viability Measurement for Pressure Ulcer Prevention in Spinal Cord Injury. J Phys Med Rehabil Disabil 1: 002.

7. Cardenas DD, Hoffman JM, Kirshblum S, McKinley W (2004) Etiology and incidence of rehospitalization after traumatic spinal cord injury: a multicenter analysis. Arch Phys Med Rehabil 85: 1757-1763.

8. National Institute of Health and Care Excellence (NICE) (2014) Costing statement: Pressure ulcers Implementing the NICE guideline on pressure ulcers (CG179). National Institute of Health and Care Excellence, UK.

9. Dealey C, Posnett J, Walker A (2012) The cost of pressure ulcers in the United Kingdom. J Wound Care 21: 261-262,264,266.

10. Henzel MK, Bogie KM, Guihan M, Ho CH (2011) Pressure ulcer management and research priorities for patients with spinal cord injury: consensus opinion from SCI QUERI Expert Panel on Pressure Ulcer Research Implementation. J Rehabil Res Dev 48: xi-xxxii.

11. Schubert V (2000) The influence of local heating on skin microcirculation in pressure ulcers, monitored by a combined laser Doppler and transcutaneous oxygen tension probe. Clin Physiol 20: 413-421.

12. Jan YK, Brienza D (2006) Technology for Pressure Ulcer Prevention. Topics in Spinal Cord Injury Rehabilitation 11: 30-41.

13. Bogie KM, Triolo RJ (2003) Effects of regular use of neuromuscular electrical stimulation on tissue health. J Rehabil Res Dev 40: 469-475.

14. Levine SP, Kett RL, Wilson BA, Cederna PS, Gross MD, et al. (1989) Ischial blood flow of seated individuals during electrical muscle stimulation. In: Proceedings of the Tenth Annual Conference on Rehabilitation Technology; San Jose, CA, USA. Pg: 642-644.

15. Stern MD (1975) In vivo evaluation of microcirculation by coherent light scattering. Nature 254: $56-58$

16. Rajan V, Varghese B, van Leeuwen TG, Steenbergen W (2009) Review of methodological developments in laser Doppler flowmetry. Lasers Med Sci 24: 269-283.

17. Worsley P, Voegeli D (2013) Back to basics: biophysical methods in tissue viability research. J Wound Care 22: 434-436,438-439.

18. Schubert V, Fagrell B (1991) Postocclusive reactive hyperemia and thermal response in the skin microcirculation of subjects with spinal cord injury. Scand J Rehabil Med 23: 33-40.

19. Sonenblum SE, Vonk TE, Janssen TW, Sprigle SH (2014) Effects of wheelchair cushions and pressure relief maneuvers on ischial interface pressure and blood flow in people with spinal cord injury. Arch Phys Med Rehabil 95: 1350-1357.

20. Jan YK, Jones MA, Rabadi MH, Foreman RD, Thiessen A (2010) Effect of wheelchair tilt-in-space and recline angles on skin perfusion over the ischial tuberosity in people with spinal cord injury. Arch Phys Med Rehabil 91: 17581764 .

21. Jan YK, Brienza DM, Boninger ML, Brenes G (2011) Comparison of skin perfusion response with alternating and constant pressures in people with spinal cord injury. Spinal Cord 49: 136-141.

22. Jan YK, Crane BA (2013) Wheelchair tilt-in-space and recline does not reduce sacral skin perfusion as changing from the upright to the tilted and reclined position in people with spinal cord injury. Arch Phys Med Rehabil 94: 1207-1210.

23. Jan YK, Liao F, Jones MA, Rice LA, Tisdell T (2013) Effect of durations of wheelchair tilt-in-space and recline on skin perfusion over the ischial tuberosity in people with spinal cord injury. Arch Phys Med Rehabil 94: 667-672.

24. Jan YK, Liao F, Rice LA, Woods JA (2013) Using reactive hyperemia to assess the efficacy of local cooling on reducing sacral skin ischemia under surface pressure in people with spinal cord injury: a preliminary report. Arch Phys Med Rehabil 94: 1982-1989.

25. Deitrick G, Charalel J, Bauman W, Tuckman J (2007) Reduced arterial circulation to the legs in spinal cord injury as a cause of skin breakdown lesions. Angiology 58: 175-184.
26. Tzen YT, Brienza DM, Karg P, Loughlin P (2010) Effects of local cooling on sacral skin perfusion response to pressure: implications for pressure ulcer prevention. J Tissue Viability 19: 86-97.

27. Cracowski JL, Minson CT, Salvat-Melis M, Halliwill JR (2006) Methodological issues in the assessment of skin microvascular endothelial function in humans. Trends Pharmacol Sci 27: 503-508.

28. Bromley I (2008) Transcutaneous monitoring - understanding the principles. Infant 4: 95-98.

29. Evans NT, Naylor PF (1967) The systemic oxygen supply to the surface of human skin. Respir Physiol 3: 21-37.

30. Nishiyama T, Nakamura S, Yamashita K (2006) Effects of the electrode temperature of a new monitor, TCM4, on the measurement of transcutaneous oxygen and carbon dioxide tension. J Anesth 20: 331-334.

31. Huch R, Huch A, Albani M, Gabriel M, Schulte FJ, et al. (1976) Transcutaneous $\mathrm{pO}_{2}$ monitoring in routine management of infants and children with cardiorespiratory problems. Pediatrics 57: 681-690.

32. Hutchison DC, Rocca G, Honeybourne D (1981) Estimation of arterial oxygen tension in adult subjects using a transcutaneous electrode. Thorax 36 : 473-477.

33. Hughes JA, Gray BJ, Hutchison DC (1984) Changes in transcutaneous oxygen tension during exercise in pulmonary emphysema. Thorax 39: 424-431.

34. Severinghaus JW, Stafford M, Bradley AF (1978) tcPCO2 electrode design, calibration and temperature gradient problems. Acta Anaesthesiol Scand Suppl 68: 118-122

35. Goldman MD, Gribbin HR, Martin RJ, Loh L (1982) Transcutaneous Pco2 in adults. Anaesthesia 37: 944-946.

36. Binder N, Atherton H, Thorkelsson T, Hoath SB (1994) Measurement of transcutaneous carbon dioxide in low birthweight infants during the first two weeks of life. Am J Perinatol 11: 237-241.

37. Dowd GS, Linge K, Bentley G (1983) Measurement of transcutaneous oxygen pressure in normal and ischaemic skin. J Bone Joint Surg $\mathrm{Br}$ 65: 79-83.

38. Lagerkvist AL, Sten G, Redfors S, Holmgren D (2003) Repeated blood gas monitoring in healthy children and adolescents by the transcutaneous route. Pediatr Pulmonol 35: 274-279.

39. Chai CY, Bader DL (2013) The physiological response of skin tissues to alternating support pressures in able-bodied subjects. J Mech Behav Biomed Mater 28: 427-435.

40. Bogie KM, Nuseibeh I, Bader DL (1995) Early progressive changes in tissue viability in the seated spinal cord injured subject. Paraplegia 33: 141-147.

41. Arsenault KA, Al-Otaibi A, Devereaux PJ, Thorlund K, Tittley JG, et al. (2012) The use of transcutaneous oximetry to predict healing complications of lower limb amputations: a systematic review and meta-analysis. Eur J Vasc Endovasc Surg 43: 329-336

42. Mawson AR, Siddiqui FH, Connolly BJ, Sharp CJ, Summer WR, et al. (1993) Sacral transcutaneous oxygen tension levels in the spinal cord injured: risk factors for pressure ulcers? Arch Phys Med Rehabil 74: 745-751.

43. Bogie KM, Nuseibeh I, Bader DL (1995) Early progressive changes in tissue viability in the seated spinal cord injured subject. Paraplegia 33: 141-147.

44. Kim J, Ho CH, Wang X, Bogie K (2010) The use of sensory electrical stimulation for pressure ulcer prevention. Physiother Theory Pract 26: 528-536.

45. Liu MH, Grimm DR, Teodorescu V, Kronowitz SJ, Bauman WA (1999) Transcutaneous oxygen tension in subjects with tetraplegia with and without pressure ulcers: a preliminary report. J Rehabil Res Dev 36: 202-206.

46. Mawson AR, Siddiqui FH, Connolly BJ, Sharp CJ, Stewart GW, et al. (1993) Effect of high voltage pulsed galvanic stimulation on sacral transcutaneous oxygen tension levels in the spinal cord injured. Paraplegia 31: 311-319. 
47. Wan S, Jaenicke KF, Parrish JA (1983) Comparison of the erythemogenic effectiveness of ultraviolet-B (290-320 nm) and ultraviolet-A $(320-400 \mathrm{~nm})$ radiation by skin reflectance. Photochem Photobiol 37: 547-552.

48. Dawson JB, Barker DJ, Ellis DJ, Grassam E, Cotterill JA, et al. (1980) A theoretical and experimental study of light absorption and scattering by in vivo skin. Phys Med Biol 25: 695-709.

49. Andersen PH, Bjerring $\mathrm{P}$ (1990) Noninvasive computerized analysis of skin chromophores in vivo by reflectance spectroscopy. Photodermatol Photoimmunol Photomed 7: 249-257.

50. Hagisawa S, Ferguson-Pell M, Cardi M, Miller SD (1994) Assessment of skin blood content and oxygenation in spinal cord injured subjects during reactive hyperemia. J Rehabil Res Dev 31: 1-14.

51. Liu LQ, Nicholson GP, Knight SL, Chelvarajah R, Gall A, et al. (2006) Interface pressure and cutaneous hemoglobin and oxygenation changes under ischial tuberosities during sacral nerve root stimulation in spinal cord injury. $J$ Rehabil Res Dev 43: 553-564.

52. Feather JW, Hajizadeh-Saffar M, Leslie G, Dawson JB (1989) A portable scanning reflectance spectrophotometer using visible wavelengths for the rapid measurement of skin pigments. Phys Med Biol 34: 807-820.

53. Berardesca E, Maibach $\mathrm{HI}$ (1988) Bioengineering and the patch test. Contact Dermatitis 18: 3-9.

54. Ferguson-Pell M, Hagisawa S (1995) An empirical technique to compensate for melanin when monitoring skin microcirculation using reflectance spectrophotometry. Med Eng Phys 17: 104-110.

55. Sprigle S, Linden M, Riordan B (2002) Characterizing reactive hyperemia via tissue reflectance spectroscopy in response to an ischemic load across gender, age, skin pigmentation and diabetes. Med Eng Phys 24: 651-661.

56. Jan YK, Crane BA, Liao F, Woods JA, Ennis WJ (2013) Comparison of muscle and skin perfusion over the ischial tuberosities in response to wheelchair tilt-in-space and recline angles in people with spinal cord injury. Arch Phys Med Rehabil 94: 1990-1996.

57. Li Z, Leung JY, Tam EW, Mak AF (2006) Wavelet analysis of skin blood oscillations in persons with spinal cord injury and able-bodied subjects. Arch Phys Med Rehabil 87: 1207-1212.
58. Sowa MG, Leonardi L, Payette JR, Fish JS, Mantsch HH (2011) Near infrared spectroscopic assessment of hemodynamic changes in the early post-burn period. Burns 27: 241-249.

59. Reenalda J, Van Geffen P, Nederhand M, Jannink M, IJzerman M, et al (2009) Analysis of healthy sitting behavior: interface pressure distribution and subcutaneous tissue oxygenation. J Rehabil Res Dev 46: 577-586.

60. Smit CA, Zwinkels M, van Dijk T, de Groot S, Stolwijk-Swuste JM (2013) Gluteal blood flow and oxygenation during electrical stimulation-induced muscle activation versus pressure relief movements in wheelchair users with a spinal cord injury. Spinal Cord 51: 694-699.

61. Bates-Jensen BM, McCreath HE, Kono A, Apeles NC, Alessi C (2007) Subepidermal moisture predicts erythema and stage 1 pressure ulcers in nursing home residents: a pilot study. J Am Geriatr Soc 55: 1199-1205.

62. Bates-Jensen BM, McCreath HE, Pongquan V, Apeles NC (2008) Subepidermal moisture differentiates erythema and stage I pressure ulcers in nursing home residents. Wound Repair Regen 16: 189-197.

63. Guihan M, Bates-Jenson BM, Chun S, Parachuri R, Chin AS, et al. (2012) Assessing the feasibility of subepidermal moisture to predict erythema and stage 1 pressure ulcers in persons with spinal cord injury: a pilot study. $J$ Spinal Cord Med 35: 46-52.

64. Ching CT, Chou MY, Jiang SJ, Huang SH, Sun TP, et al. (2011) Tissue electrical properties monitoring for the prevention of pressure sore. Prosthet Orthot Int 35: 386-394.

65. Harrow JJ, Mayrovitz HN (2014) Subepidermal moisture surrounding pressure ulcers in persons with a spinal cord injury: a pilot study. J Spinal Cord Med 37: 719-728.

66. Bates-Jensen BM, McCreath HE, Pongquan V (2009) Subepidermal moisture is associated with early pressure ulcer damage in nursing home residents with dark skin tones: pilot findings. J Wound Ostomy Continence Nurs 36 277-284.

67. Swisher SL, Lin MC, Liao A, Leeflang EJ, Khan Y, et al. (2015) Impedance sensing device enables early detection of pressure ulcers in vivo. Nat Commun 6: 6575 . 